\title{
TUNIS'S NEW MOSQUES CONSTRUCTED BETWEEN 1975 AND 1995: MORPHOLOGICAL KNOWLEDGE
}

\author{
Imen Cherif \\ National School of Architecture and Urbanism \\ University of Carthage \\ Tunis, Tunisia \\ Imencherif_archi@yahoo.com \\ Najla Allani Bouhoula \\ National School of Architecture and Urbanism \\ University of Carthage \\ Tunis, Tunisia \\ Najla.allani@gmail.com
}

Received: March 27 2015 ; Accepted: April 27 ${ }^{\text {th }} 2015$; Available Online: June $15^{\text {th }} 2015$

\begin{abstract}
The mosque has always been a prominent unit that used to structure the old Islamic cites. Its architecture through the Muslim world has always aroused the interest of many researchers. Actually, mosques are still built while undergoing the changes which occurred on the modern societies. However, only few research who have been interested in the new mosques. This paper targets the architecture of mosques built in Tunis governorate between 1975 and 1995. Through a morphological analysis of 24 mosques we were able to determine their identity and their morphological structure. According to their form and position, we discovered classes of specimen and classes of segments. Our corpus presents several constants and variations that we can explain though the introduction of some extrinsic attributes. In fact, these architectural objects possess some morphological specifications related to some urban, functional and historical factors.
\end{abstract}

Keywords: New mosque; Tunis governorate; morphological structure; form; position

\section{Introduction}

The mosque is considered as the main manifestation of Islamic art. There are many researches that were interested in these architectural objects. These studies have been essentially focused on the former mosques. Some of them took an interest in their spatial structure [1] others focused in their stylistic [2][3][4][5]. Nevertheless, some researches were interested in the contemporary mosques [6][7]. Whereas researches on Tunisian mosques have remained limited to that which concerning the ancient mosques [8][9][10][11].

In this research we are interested in identifying the morphological structure of the mosques spaces constructed in Tunis's govemorate between 1975 and 1995 [12].This is why we used the method of morphological analysis which allows the comprehension of the morphological organization of the man-made objects [13]. This method reveals the rules that govern the conformations. Thus, while revealing the constants and changes forms, it allows to determinate the identity classes of studied objects. So we can identify the distinctive features through analysis and morphological decomposition resulting in an intelligible classification.
Applied to a corpus of 24 mosques, this method allows us to define their characteristics in a systematic identification process. It is therefore applied to understand the combinatorial systems of forms. In fact, we assume that there is a logical formal organization of mosques built in Tunis from 1975 to 1995 that we are trying to reveal and explain through the plans and the facades. We can then relate the intrinsic morphological knowledge with other fields of knowledge; this may provide extrinsic explanations in what we have observed. So we can identify the relationship that may exist between these architectural objects and its physical, temporal and cultural context.

\section{General Context of Study}

To better understand our object of study, we propose first a definition of the mosque. In fact the Arabic word "Masjid", Mosque, combines the root of the word "Sajda" that means prostrate by putting the forehead to the ground and the location prefix $\mathrm{m}$. So it refers to a place for inclination conformed to the attitude of prayer. The mosque is a worship place reserved for communal Muslims prayer. With time and gradually with the expansion of Muslim community, the term "Masjid" was reserved to the little mosque, the neighborhood or local mosque 
and where people gather for prayer five times per day except on Friday when they head to the "masjid Djami" or simply "Al-Jami" that refer to the main or the great mosque, a meeting and a gathering place where the "Imam" led the prayer and addresses a speech ("Khutbah") to the faithful. The main type of mosques identified in Tunisia is the hypostyle Mosque which is characterized by "Arab" or "Hypostyle" plan. The Great Mosque of Kairouan in Tunisia is one of the oldest places of worship in the Islamic world. Built in $670 \mathrm{AD}$, it was the first constructed mosque in North Africa and has served as a model in the construction of all later mosques in the Maghreb. These mosques have rectangular plans with an enclosed courtyard and a covered prayer hall whose roof is supported by numerous columns and supports. This kind of mosque has the flexibility to expand according to the population growth.

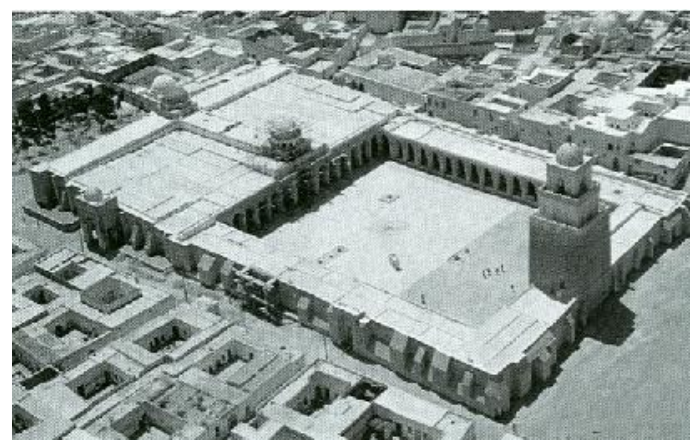

Figure 1. Old aerial view of the Great Mosque of Kairouan dating from 1964

(Source:

http://fr.wikipedia.org/wiki/Grande_Mosqu\%C3\%A9e_de _Kairouan\#/media/File:Vue_a\%C3\%A9rienne_de_la_Gra nde_Mosqu\%C3\%A9e_de_Kairouan.jpg)

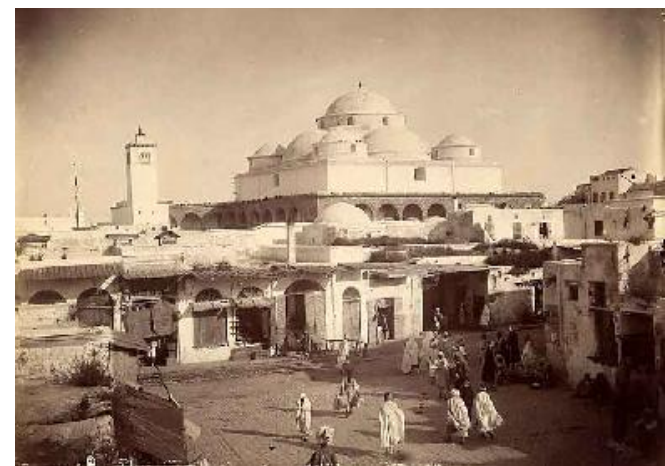

Figure 2. Old photograph dating from 1890 showing the Bab Souika place and the mosque of Mohamed Bey Almouradi

(Source:

http://commons.wikimedia.org/wiki/File:Bab_Souika_et _mosqu\%C3\%A9e.jpg)

Even though Tunisia was part of the Ottoman Empire going back to the 16th century, no mosque has been constructed according to the ottoman model only one attempt at the Mohamed Bey AlMouradi Mosque (1692 AD) that was uncompleted (without minaret). The Turkish contribution has remained limited to the addition of architectural or decorative elements.

The main components of mosque in Tunisia are: -The prayer hall: it is a covered space and not necessarily enveloped, intended to receive the faithful for the communal prayer. The orientation is the only directive required for the place of prayer which must be oriented to the "qibla". The prayer hall brings together some elements as the "Mihrab" (a niche defining the direction to which faithful must turn toward for praying) and the "Minbar" (a pulpit which is usually made of wood, it takes the form of a flight of steps. It is used by the "Imam" to address the faithful during his sermon "khutba" for Friday prayers.)

-The gallery: it is colonnaded or arcaded porticoes, it surrounds one or more of the courtyard side and ensure the passage from covered area to open space.

-The courtyard: it is an uncovered area; it is a transient space between the outside and the prayer hall. It allows extension of area of prayer especially in warm periods.

-The ablutions room: This is a space reserved for ablution; the faithful can be put in a state of ritual purity before performing his prayer. It may be at the entry or in front of the building. A fountain placed in the middle of the courtyard can also be used for ablution.

-Minaret: It is a tower used to call faithfuls to prayer five times a day by a "muezzin" also the Minaret seems to have a signaling role so it marks the location of the mosque in the agglomeration and it indicates the presence of Islam in the city.

\section{Morphological Analysis}

Mosques constructed in the governorate of Tunis between 1975 and 1995 are architectural forms considered as "human facts" that can be the subject of a morphological study. Certainly all these specimens have the same "nominal identity" defined as sorts or kinds of things that have the same name. But do not necessarily have the same morphological identity. Hence the need to understand their morphological characteristics deemed to be significant and relevant.

To properly conduct this study corpus must be homogeneous, for this all specimens have the same nominal identity, built in the governorate of Tunis in the same period (between 1975 and 1995). It must also be representative as the specimens are distributed evenly on the card and the date of 
building permits is included in the study period. Then the corpus must be manageable containing 24 mosques, a sufficient number to properly conduct this study. In this work the study materials are composed of Plans and facades.

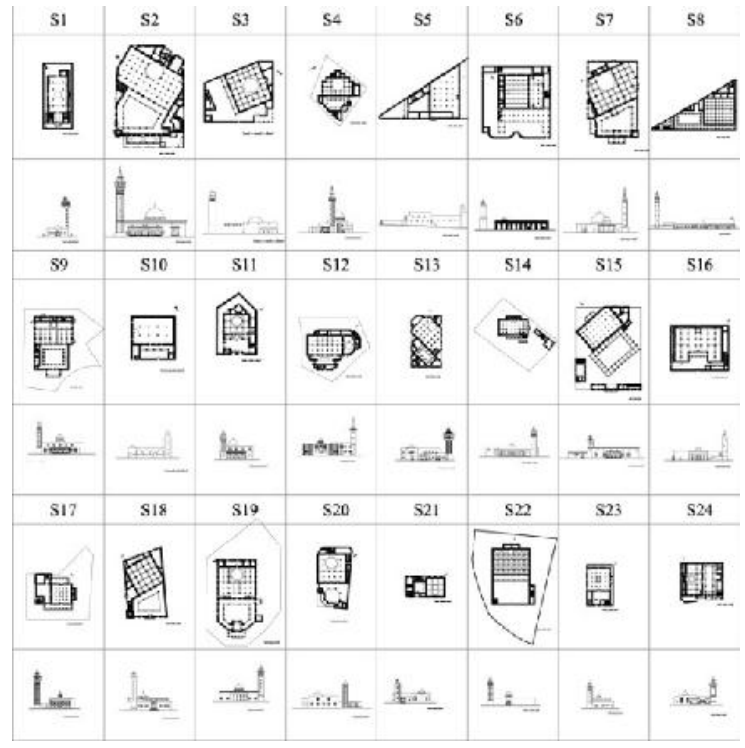

Figure 3. The study materials (Source: drawn by the author)

This analysis is conducted in 4 steps :

-The first is the study of the spatial structure for each specimen in the collection, and it appeals to the observation of space's occupancy modalities to identify the spatial conformations without materialized limits. That allows the determination of the spatial relationships according to the positions of elements. A structural modeling was used to determine the model or models of the morphological structure of mosques. This has contributed to the determination of the operating mode according to which the elements are articulated.

- The second level concerns the study of the constituent elements defined above. The aim is to establish a catalog of basic forms of these components. However, a constituent element may be composed of a set of elements; in this case it will be subject to a decomposition study which is based on the observation and identification of obvious discontinuities and comparative decomposition according to a homology operator based on the conformation of the segment and completed by the usage. That allows to catalogue by class of homologous segments and conduct a classification study for each group of homologous segments according to the form and the position.

-The third level of analysis is devoted to an exploratory study of facades; whose purpose is to check whether the functional continuity established in the plane coincides with the formal continuities of the facade. This step appealed to an overall decomposition to project the codification already established in the plan and then a Checking of the correspondence between the continuities in plan and those in facade.

- The fourth and the final level is an essay of explanation of the analysis's results by introducing extrinsic data such as orientation, accessibility, shape and proportion of the plot, in order to understand the spatial conformation of the mosque constructed in Tunis's governorate between 1975 and 1995.

\section{Study of the Morphological Structure (Spatial Structure)}

Mosques are architectural conformations and composed entities. They are consisting of contiguous elements which are not organized in coincidental internal structure. So we are trying to understand the modalities of their spatial occupation. To properly carry out this analysis, all specimens $S$ are positioned so that the wall of the "qibla" is placed horizontally and the "qibla" is directed upward.

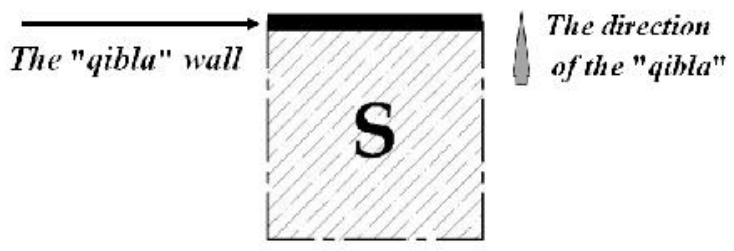

Figure 4. The positioning of specimens (Source: drawn by the author)

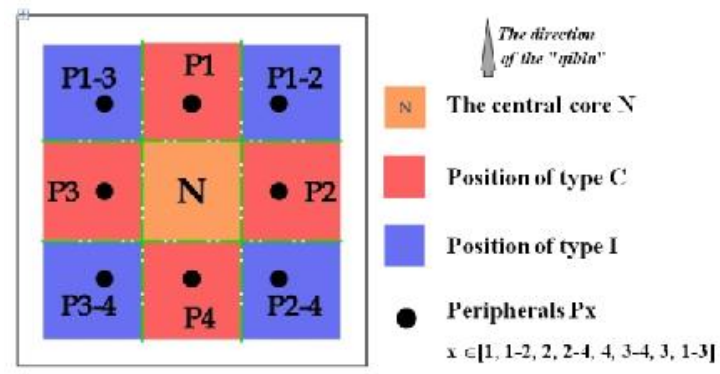

Figure 5. Positions of peripherals Px (Source: drawn by the author)

Each specimen of the collection is composed of a main element the central core $\mathrm{N}$ and a set of peripherals $\mathrm{Px}$ that surround it. The central core $\mathrm{N}$ is represented by a colored square in orange while peripherals Px are represented by black dots. They are distributed around the central core $\mathrm{N}$ in 8 positions. As shown in figure 4 , they are regrouped in two categories: 
- Peripheral Pc which positions are on the side of central core $\mathrm{N}$ and are colored on red; they are peripherals positions of type $C$.

- Peripheral Pi colored in blue, which positions are intermediate and intersect the positions of type C; they are peripherals position of type I.

So we consider that for each specimen in the collection there is a central core $\mathrm{N}$ which makes the unity and homogeneity of objects of study; and peripherals Px are implanted in relation with the central core $\mathrm{N}$. We suppose that the position of peripherals $\mathrm{Px}$ relative to the central core $\mathrm{N}$ is meaningful, an hypothesis to be tested later.

The position homology of peripherals allows modeling the spatial structure of our corpus of study. However determining the structural model or models of the mosque requires first the identification of the central core $\mathrm{N}$, the determination of peripherals and then the qualification of position relative for each identified peripheral.

Upon identifying the central core $\mathrm{N}$, the interest is taken in the determination and the delimitation of the central core $\mathrm{N}$ in each specimen of the collection. $\mathrm{N}$ is the main core of the mosque. It is a covered and a dominant element; it is identified by its preponderance and important proportions in relation to the other entities.

Peripherals Px are elements which surround the central core N. We consider " $n$ " the number of the peripherals Px which varies between 0 and 8 in function of the number of the positions that $P x$ occupy. So the spatial structure of the mosque relative to the number of peripherals $P x$ is:

$$
\mathrm{N}+\mathrm{nPx} \text { with } 0 \leq \mathrm{n} \leq 8
$$

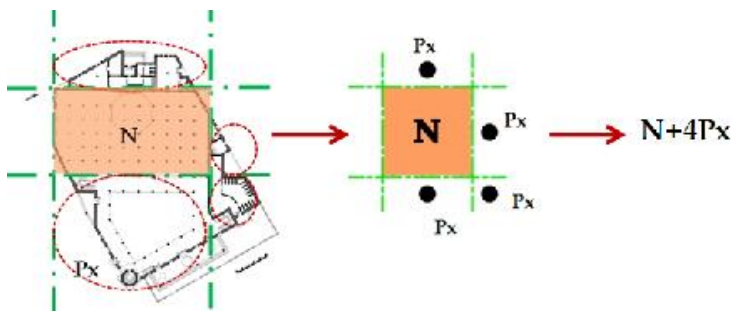

Figure 6. Spatial structure of the specimen $\mathrm{S} 2$ relative to the number of its peripherals (Source: drawn by the author)

Analysis then focused on the qualification of the positions of peripherals Px. When peripheral Px is in the areas of $C$-type positions, it is a peripheral position $\mathrm{C}(\mathrm{Pc})$ and when it is in the areas of I-type positions, it is a peripheral position I $(\mathrm{Pi})$. Pc has 4 peripherals whose positions are $\mathrm{P} 1, \mathrm{P} 2, \mathrm{P} 3$ and $\mathrm{P} 4$ and $\mathrm{Pi}$ has 4 peripherals whose positions are $\mathrm{P} 1-2$, $\mathrm{P} 2-4, \mathrm{P} 3-4$ and $\mathrm{P} 1-3$. $\mathrm{PC}$ and $\mathrm{Pi}$ have respectively a number $n$ ' and n" of positions. So the spatial structure of the mosque relative to the positions of peripherals $\mathrm{Px}$ is:

$$
\mathrm{N}+\mathrm{n}^{\prime} \mathrm{PC}+\mathrm{n}^{\prime} \mathrm{Pi} \text { with } 0 \leq \mathrm{n}^{\prime} \leq 4 \text { and } 0 \leq \mathrm{n}^{\prime} \leq 4
$$

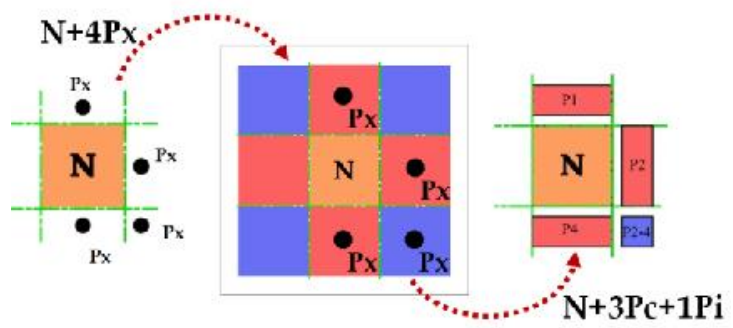

Figure 7. Spatial structure of specimen $\mathrm{S} 2$ relative to positions of its peripherals (Source: drawn by the author)

Thus there are different scenarios of morphological structures of mosques; the table below identifies the various possible combinations of $\mathrm{Pc}$ and $\mathrm{Pi}$. The table below shows the different possible combinations of peripherals $\mathrm{Pc}$ and $\mathrm{Pi}$. Models found in our collection are marked in blue.

Table 1. Scenario relating to structural models

\begin{tabular}{llllll}
\hline \hline & $\mathrm{OPC}$ & $1 \mathrm{PC}$ & $2 \mathrm{Pc}$ & $3 \mathrm{Pc}$ & $4 \mathrm{Pc}$ \\
\hline \hline $\mathrm{OP}$ & $\mathrm{N}$ & $\mathrm{N}+1 \mathrm{Pc}$ & $\mathrm{N}+2 \mathrm{Pc}$ & $\mathrm{N}+3 \mathrm{Pc}$ & $\mathrm{N}+4 \mathrm{Pc}$ \\
1 & & & & & \\
$1 \mathrm{P}$ & $\mathrm{N}+1 \mathrm{P}$ & $\mathrm{N}+1 \mathrm{Pc}+1$ & $\mathrm{~N}+2 \mathrm{Pc}+1$ & $\mathrm{~N}+3 \mathrm{Pc}+1$ & $\mathrm{~N}+4 \mathrm{Pc}+1$ \\
$\mathrm{i}$ & $\mathrm{i}$ & $\mathrm{Pi}$ & $\mathrm{Pi}$ & $\mathrm{Pi}$ & $\mathrm{Pi}$ \\
$2 \mathrm{P}$ & $\mathrm{N}+2 \mathrm{P}$ & $\mathrm{N}+1 \mathrm{Pc}+2$ & $\mathrm{~N}+2 \mathrm{Pc}+2$ & $\mathrm{~N}+3 \mathrm{Pc}+2$ & $\mathrm{~N}+4 \mathrm{Pc}+2$ \\
$\mathrm{i}$ & $\mathrm{i}$ & $\mathrm{Pi}$ & $\mathrm{Pi}$ & $\mathrm{Pi}$ & $\mathrm{Pi}$ \\
$3 \mathrm{P}$ & $\mathrm{N}+3 \mathrm{P}$ & $\mathrm{N}+1 \mathrm{Pc}+3$ & $\mathrm{~N}+2 \mathrm{Pc}+3$ & $\mathrm{~N}+3 \mathrm{Pc}+3$ & $\mathrm{~N}+4 \mathrm{Pc}+3$ \\
$\mathrm{i}$ & $\mathrm{i}$ & $\mathrm{Pi}$ & $\mathrm{Pi}$ & $\mathrm{Pi}$ & $\mathrm{Pi}$ \\
$4 \mathrm{P}$ & $\mathrm{N}+4 \mathrm{P}$ & $\mathrm{N}+1 \mathrm{Pc}+4$ & $\mathrm{~N}+2 \mathrm{Pc}+4$ & $\mathrm{~N}+3 \mathrm{Pc}+4$ & $\mathrm{~N}+4 \mathrm{Pc}+4$ \\
$\mathrm{i}$ & $\mathrm{i}$ & $\mathrm{Pi}$ & $\mathrm{Pi}$ & $\mathrm{Pi}$ & $\mathrm{Pi}$ \\
\hline
\end{tabular}

Source: table taped by the author

In order to understand the modalities of spatial occupancy of the peripherals Px, the data are processed by seriation. In fact, it tends to streamline the mechanism of visual decomposition that remains subjective and subject to several assumptions. So the results obtained are more objective. For this, we chose to use the software BSK.

First an Excel table is typed. The first line is reserved for attributes and the first column is reserved for specimens. As the collection contains 24 specimens (from S1 to S24), the table has 24 rows. The attributes used are the eight positions of peripheral Px. Each cell of the table is coded by a series of numbering 0 and 1 depending on absence and presence of the attribute in question. This program class 0 and 1 by seriation of rows and columns. The result is presented in graphs which regroups the corresponding specimens in classes By comparing the three graphics which are results of objective interpretation (The graph BSK, the 
corresponding Excel table and curves of specimens measuring inter- specimens and intra-attributes), four major classes or families of specimens are identified. Each family can be subject to a second degree of division into subsets of specimens. Common attributes exist in the four classes but other variable attributes distinguish them.

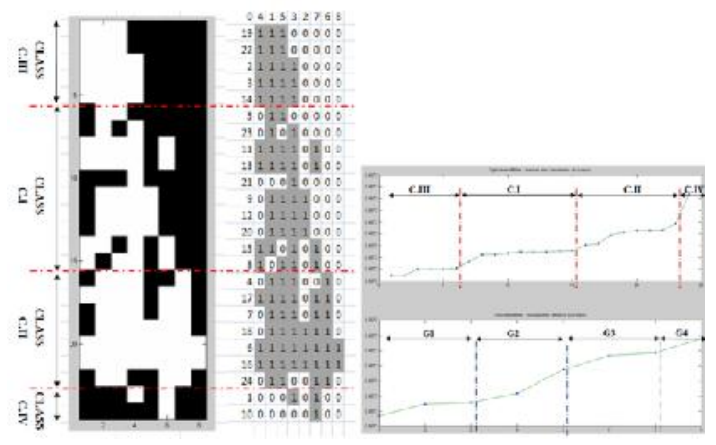

Figure 8 . Results of data processing seriation (Source: by the author)

Table 2. Specimens of each classes

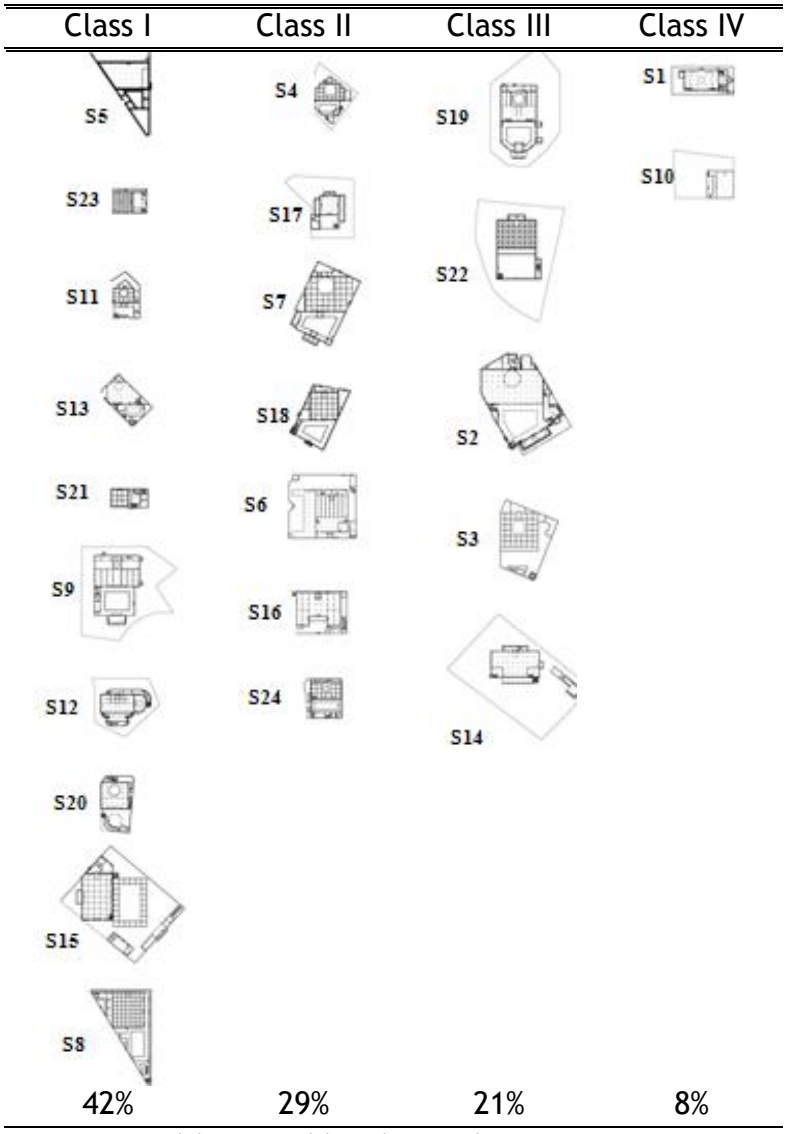

Source: table taped by the author

At this stage a structural organization of specimens is defined. The production of knowledge around this series of objects that have the same nature is based on classifying methods. The spatial structure is described in terms of combination of elementary structured conformations. By comparing structural models with classes, we note that structural model can exist in more than one class but every class has a spatial conformation of the structural model to its own. So classes have spatial structures that converge to the same structural model while presenting spatial conformations specific to the class they belong.

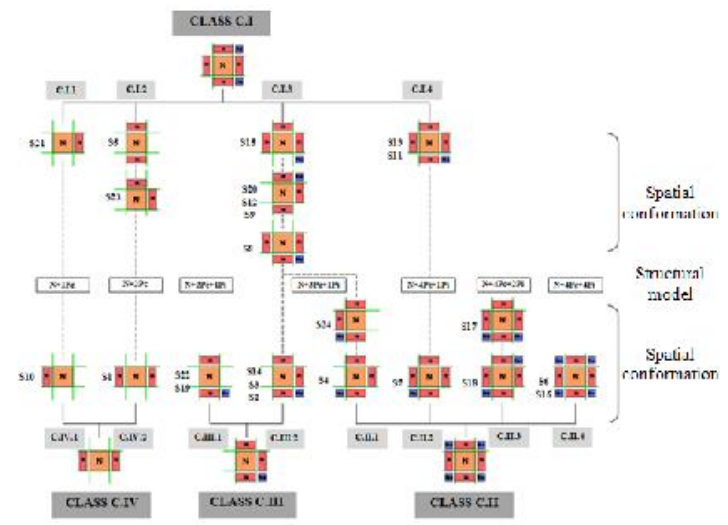

Figure 9 . Spatial conformations and structural models of mosques of gouvernorate of Tunis constructed between 1975 and 1995 (Source: by the author)

In this collection, Specimens are not homogeneous in terms of spatial conformation but have homologies positions that translate an interspecimens convergence reflecting the equivalence of morphological structure of classes. These conformations are defined as molds in which can slip architectural matter. this is what we have tried to study in the next part.

\section{Study of the Constituent Elements}

As previously detected the spatial structure of each specimen in the collection is composed of a central core $\mathrm{N}$ and a set of peripherals Px. Those are the constituent elements of the mosque.

First of all, to Study the central core $\mathrm{N}$ according to its form and its position in the parcel, each spatial conformation of $\mathrm{N}$ in the collection is identified. Then the gathered forms are compared between them in order to be classified into groups of forms. Also the classification of this conformation according to the way of occupancy in the plot has showed that the mode of implementation found for almost sub rectangular shapes is that adjacent to one or more sides of the plot. It is therefore more likely to have a central core $\mathrm{N}$ irregularly shaped when it is implanted adjacent to the plot. Also the most common implementation mode for rectangular shapes is that inside of the plot. So the positioning of the central core $\mathrm{N}$ in the plot affects its shape. 
The second elements studied are the peripherals Px. those represent a compound whole; so they can constitute a unit of study subject to an analytical decomposition. This aims to determine the segments that characterize the morphology of peripherals Px. The morphological analysis is used to understand and identify the parties in the whole and the whole in parts. So, principle of segmentation or decomposition is the spotting of obvious discontinuities or lysis that governs peripherals Px. Lysis is a perceptible mean of delimitation or boundary between adjacent segments.

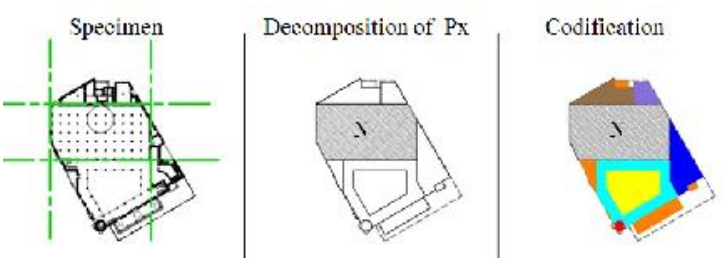

Figure 10 . Analytical decomposition of peripherals PX (Source: drawn by the author)

The identified elements are classified into groups of homologous segments according to an homology descriptor which should be strictly defined and must ensure a bijective correspondence relation from one peripheral to another, segment by segment and between each segment of different peripherals. In our study, we specify that the equivalence relationship between the segments is based on the conformation of the segment and supplemented by the space usage.

Table 3. Color codification of homologous segments of peripherals $\mathrm{Px}$ with presenting function

\begin{tabular}{|c|c|c|}
\hline Attribute & Name & "Conformation/space usage \\
\hline & $\bar{C}$ & Discovered element (courtyard) \\
\hline & G & $\begin{array}{l}\text { Covered and open element; } \\
\text { separating } \mathrm{N} \text { (central core) and } \\
\mathrm{C} \text { (courtyard) }\end{array}$ \\
\hline & M & $\begin{array}{l}\text { Dominant vertical element } \\
\text { (Minaret) }\end{array}$ \\
\hline & I & $\begin{array}{l}\text { Alveolate element directly related } \\
\text { to N (the room of the "imam") }\end{array}$ \\
\hline & A & $\begin{array}{l}\text { Alveolate element(the ablution } \\
\text { room) }\end{array}$ \\
\hline & DE & Input device \\
\hline & $\mathrm{H}$ & $\begin{array}{l}\text { transitional element; between } \mathrm{N} \\
\text { and other segments (Hall) }\end{array}$ \\
\hline & $\mathrm{J}$ & The rest \\
\hline
\end{tabular}

Source: table taped by the author

So a catalog of basic forms of each group of homologous segments can be drawn up. These are classified according to their shape and their position relative to the central core $\mathrm{N}$. Forms of elementary conformations are classified manually so that we get classes of same forms or equal. Then to further characterize the position of the segment through the collection, we conducted a data processing by seriation. The result showed the existence of groups of positions according to their frequency for each segment. The classificatory study of some examples of homologous segments groups according to the shape and position of their conformations are reported in the following:

-The study of the segments $M$ (Minaret) showed that it exists in each specimen of the collection. The shape particularly found is the square then the octagon and and rarely the circle.

Table 4. Classification forms of segment $M$ (Minaret)

\begin{tabular}{l}
$\begin{array}{l}\text { Form's } \\
\text { conformation }\end{array}$ \\
\hline \hline $\begin{array}{l}\text { Rectangular } \\
\text { Sub- } \\
\text { rectangular } \\
\text { triangular } \\
\text { Sub-triangular }\end{array}$ \\
Square
\end{tabular}

Source: by the author

The result of data processing by seriation showed that there are 4 classes of segments and 4 groups of positions: the first corresponds to strongly present positions (P4). The second moderately present positions (P2). The third weakly present positions $(\mathrm{P} 2-4)$ and the fourth rarely present positions (P1, P3, and P1-3).

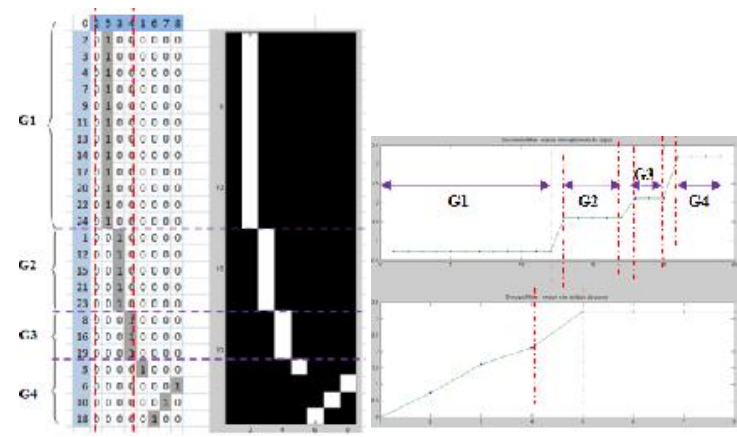

Figure 11 . Data processing seriation (Source: by the author)

- The study of the segments $C$ (Courtyard) showed that some units of study have more than one segment C while other may not have it. Classification table of elementary forms of this segment showed that it is mostly irregular shaped. 
Table 5. Classification form of segment C ( Courtyard)

\begin{tabular}{l}
\hline Form's conformation \\
\hline Rectangular
\end{tabular}

Source: by the author

Also, the result of data processing showed that most segments occupy the C-type position and more precisely the position $\mathrm{P} 2, \mathrm{P} 3$ and $\mathrm{P} 4$ and never $\mathrm{P} 1$. The position P4 is the most frequent. However, a class with segments that occupy more than one position is found.

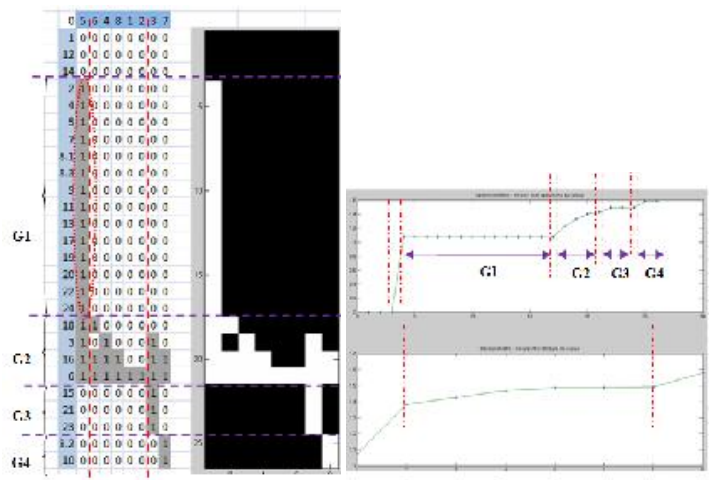

Figure 12 . Data processing seriation (Source: by the author)

-Elementary forms of the segment $G$ (Gallery) are classified according to their overall conformations and according to their conformations in relation to the courtyard segment. For example the group of rectangular shapes has 4 subsets according to the conformation of gallery segment in relation with the courtyard segment. In fact, there are subsets which contain segments $G$ located on one side, on two sides, on three sides or on four sides of the courtyard.
Table 6. Classification form of segment G (Gallery)

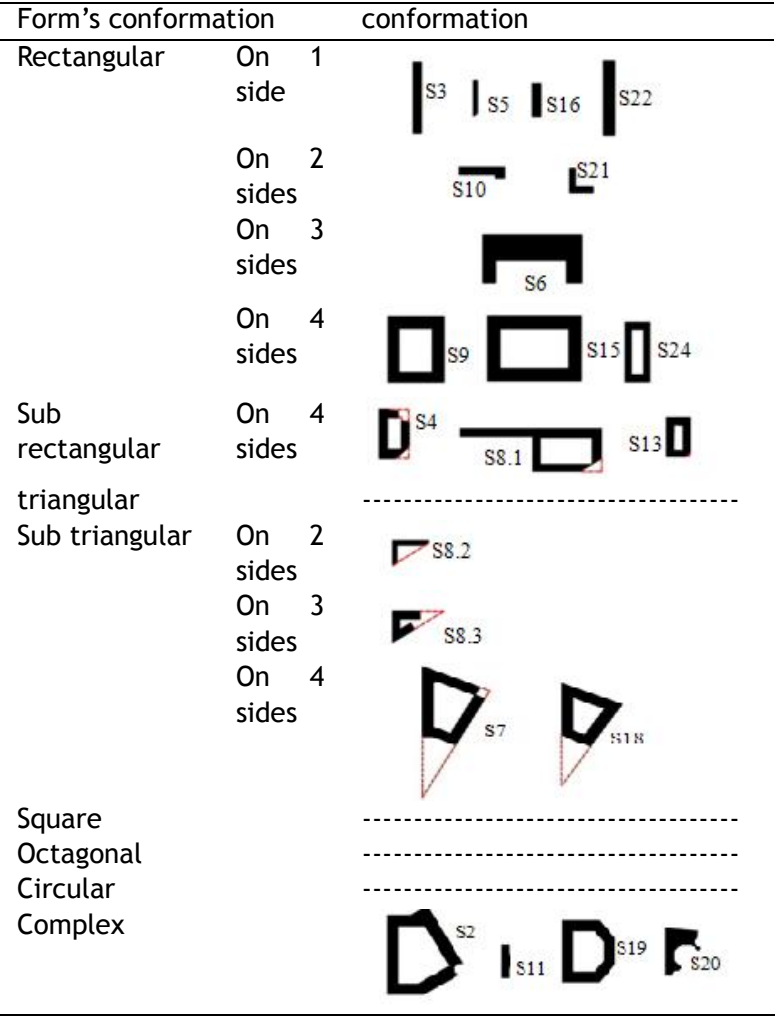

Source: by the author

Also there are four classes of segments $G$ according to their positions around the central core $\mathrm{N}$. the first includes only the segments having the position $\mathrm{P} 4$, the second contains segments which have positions $\mathrm{P} 2, \mathrm{P} 2-4$ and $\mathrm{P} 4$. The third group has segments in the position P4 and P3-4. The fourth contains segments having position $\mathrm{P} 3, \mathrm{P} 1-3$ and $\mathrm{P} 3-4$.

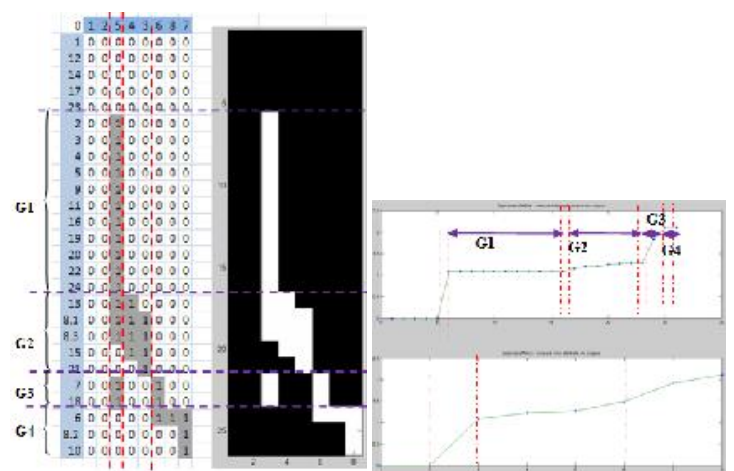

Figure 13. Data processing seriation (Source: by the author)

-Most of segments I (the room of "Imam") have a rectangular or sub-triangular shape. But also they can have sub-rectangular, triangular or complex shapes. 
Table 7. Form of segment I (Room of "Imam”)

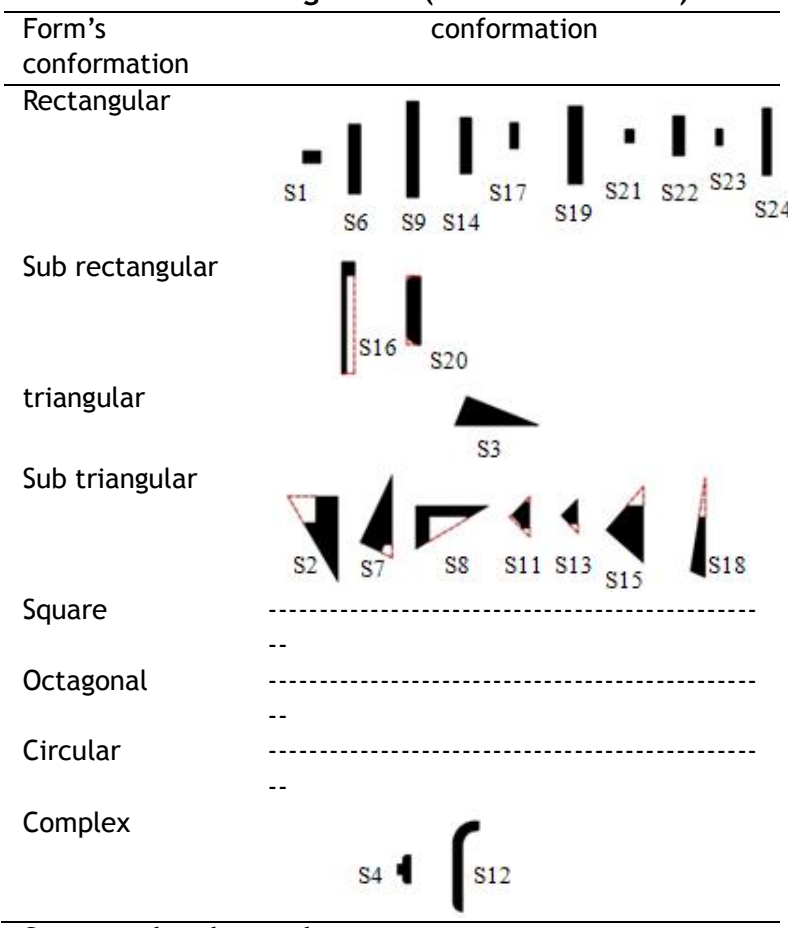

Source: by the author

Also there are three groups of segments I relative to the positions. The first contains segments in $\mathrm{P} 1$ position, the second includes segment which occupies more than one position ( $P 1$, P1-2 and P2). The third contains segments in P3position.

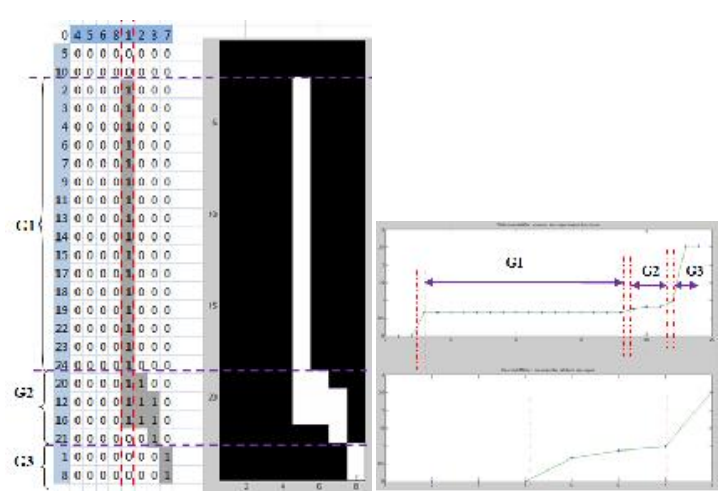

Figure 14 . Data processing seriation (Source: by the author)

\section{Exploratory Study of Facades}

The exploration of facades is used to complete the knowledge achieved in the spatial study and to verify any correspondence. Indeed, a comparative decomposition has allowed identifying the central core $\mathrm{N}$ (prayer room) and understanding its position at the facade. The result shows that $\mathrm{N}$ has become a second element of importance because it is positioned in most cases in the second scanning plane (which corresponds to a position far away from the eye).

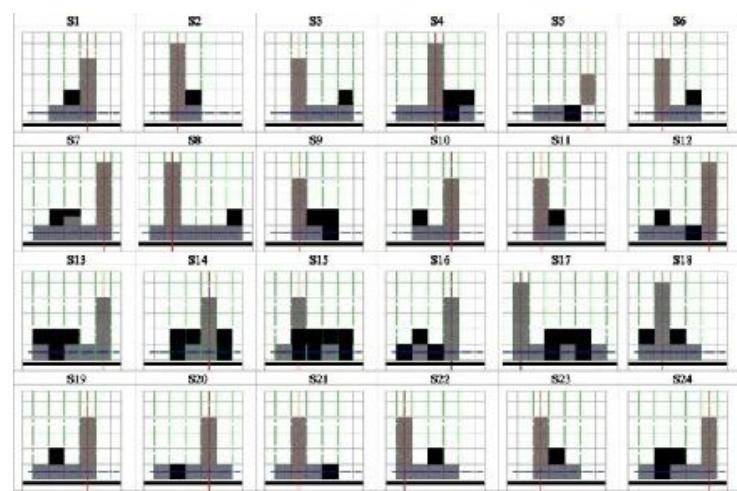

Figure 15 . Identification of the central core $\mathrm{N}$ through the collection (Source: by the author)

Contrary to the plan, it is difficult to identify the prayer room at the facade. It seems to lose its predominance. However we found the appearance of an omnipresent device that stands out among all segments. It is the minaret. Recognizable by its slender shape; it ensures a certain verticality and seems to be the most striking feature of the façade.

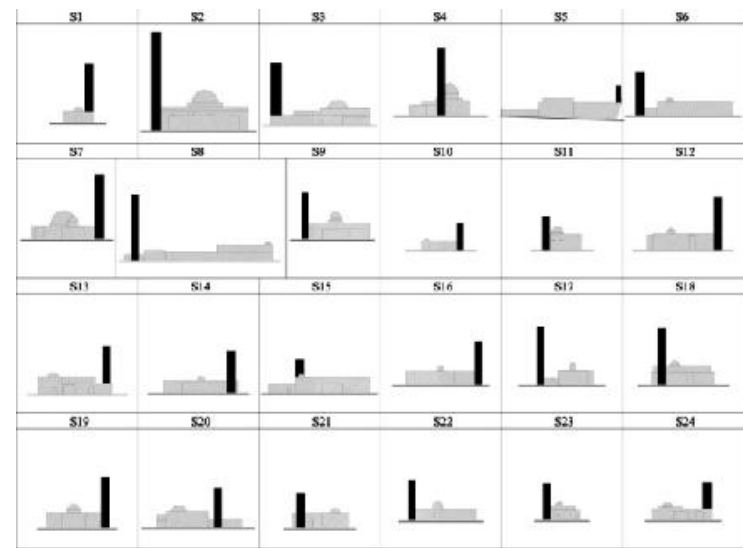

Figure 16. Identification of the segment $M$ (Minaret) through the collection (Source: by the author)

Also, the identification of homologous segments according to the same homology descriptor adopted in plan (which is based on the conformation of segment and supplemented by the usage) showed that the facade and the plan do not have the same segments. In fact, some segments have disappeared, such as the segment $C$ (court), the segment A (ablution hall) and the segment I (Room of "Imam") at the same time, others have emerged as the segment $L$ (enclosure wall.). However, other segments have persisted as the segment $M$ (Minaret), the segment DE (input device) and the segment $G$ (gallery). Moreover, some highly distinguishable segments in plan become much less in façade at a level that we could confuse them; as is the case for the segment DE (input device) and the segment $G$ (gallery). We are therefore able to 
conclude that the formal continuities of the facade do not fully coincide with those of the plan.

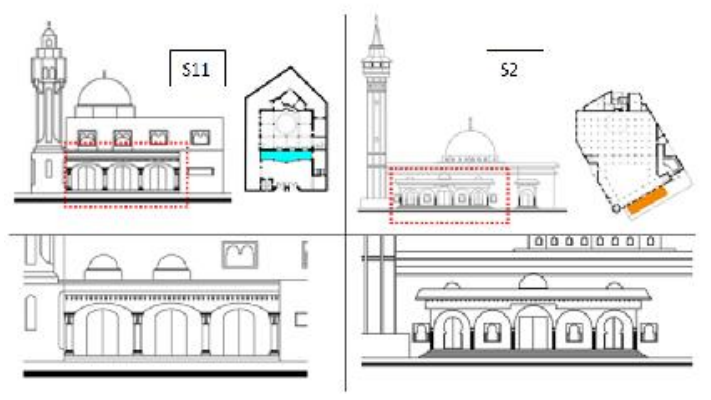

Figure 17. Comparison between the gallery of the specimen S11 and the input device of the specimen S2 (Source: by the author)

\section{Interpretive Essay by Extrinsic Attributes}

The first extrinsic attributes introduced are the access to the prayer hall and the direction of the "qibla". Those are two determining factors in the position of the segments.

In fact, on a functional level and without taking account of the direction of the "qibla", the spatial conformation of the hypostyle mosque is characterized by the succession in the order of these three elements: courtyard $(C)$, gallery $(G)$ and prayer hall $(\mathrm{N})$. To access the prayer hall, the faithful passes through a transitional space between the outside and the prayer hall, it is the courtyard or the "s'han" which is juxtaposed on one or more than one of its sides by a gallery, the latter allows the passage between the covered space which is the prayer hall and the uncovered space that is the courtyard.

By introducing the extrinsic attributes access to the prayer hall and the direction of the "qibla" the couple (Courtyard; Gallery) changes its position relative to the central core $\mathrm{N}$ (the prayer hall). We found three spatial conformations:

In the first conformation the direction of the "qibla" is parallel to the direction of the entrance to the prayer hall. Other components of the mosque, as the ablution room and minaret, are located on either side of this couple and can occupy the P4 position with the possibility of continuity in the intermediate positions $\mathrm{P} 2-4$ and $\mathrm{P} 3-4$.

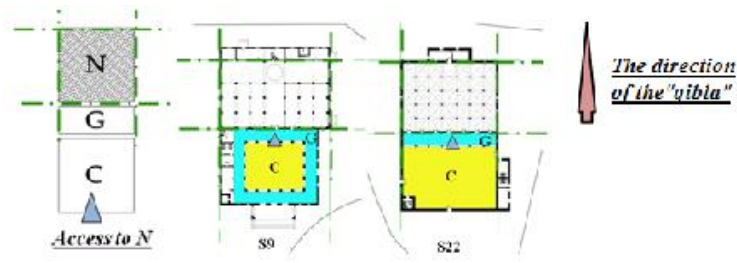

Figure 18. Example of specimens with $(C ; G)$ in $P 4$ position(Source: by the author)
So we can identify this rule:

If access to the prayer hall is parallel to the direction of the "qibla" then the couple $(C, G)$ occupies the P4 position.

In the second and the third conformation the direction of the "qibla" is perpendicular to the direction of the entrance to the central core N. In the first case the couple $(C, G)$ occupies the position $\mathrm{P} 2$ and the other components of the mosques are in $\mathrm{P} 2$ position through continuities to intermediates positions ( $\mathrm{P} 1-2$ and $\mathrm{P} 2-4)$.

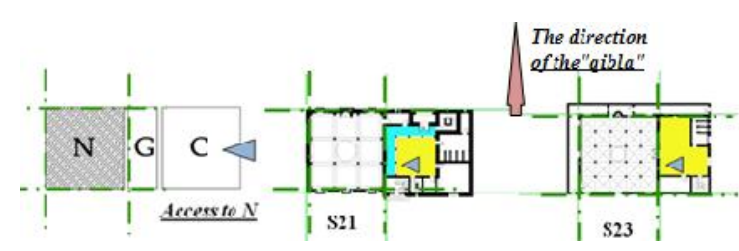

Figure 19. Example of specimens with $(C ; G)$ in $P 2$ position (Source: by the author)

In the second case, the couple $(C, G)$ occupies the $\mathrm{P} 3$ position and the other components too through continuities in intermediates positions (P1-3 and P3$4)$.
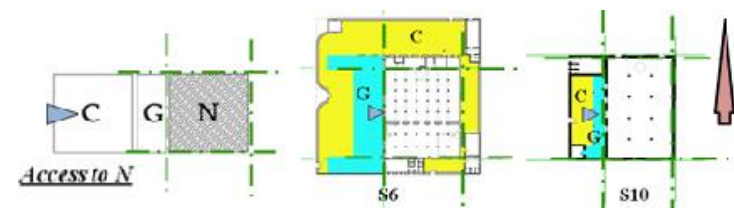

Figure 20. Example of specimens with $(C ; G)$ in $P 3$ position (Source: by the author)

So we can identify this rule:

If access to the prayer hall is perpendicular to the direction of the "qibla" then the couple $(C, G)$ occupies the position P2 or P3.

We note that the specimen S23 (Figure 19) does not have a gallery. So the couple $(C ; G)$ is not interdependent. The presence of the courtyard does not depend on the presence of the gallery but the presence of the gallery depends on the presence of the courtyard. So :

If there is gallery, there is courtyard but the opposite is not true the courtyard can exist without the gallery.

Secondly, the spatial conformations of certain segments can be explained by historical influences. Of the one part we notice that some mosques draw their forms from Arab-hypostyle mosques. 


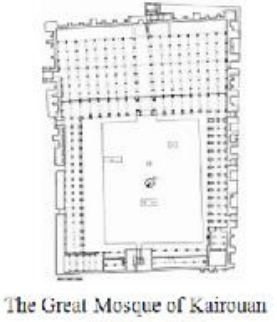

(Tunisia, 670)

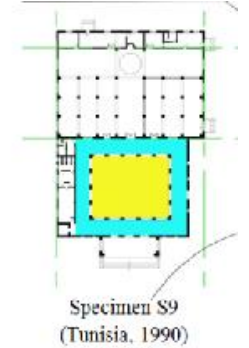

Figure 21. Example of specimen with influences to hypostyle mosques (Source: by the author)

And on the other they draw their forms from Ottoman mosques. We found that especially at the courtyard and the minaret segment. In fact, the courtyard which juxtaposes the prayer hall on more than one side is a characteristic of the Turkish mosque whereas the courtyard of the Arab hypostyle mosque is located on one side of the prayer hall. The first mosque built by the Ottoman in Tunis was that of Youssef Dey (1615), which also draws its origins from the Piali Pasha mosque built in Istanbul (1585).

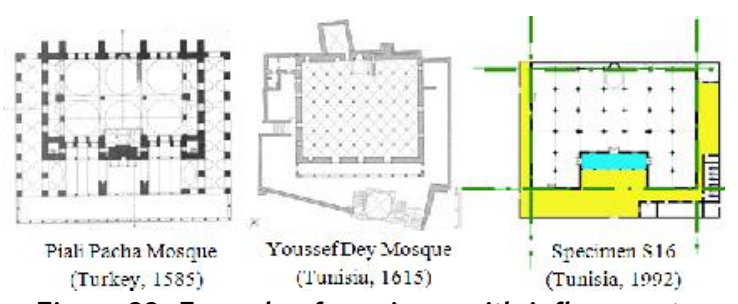

Figure 22. Example of specimen with influences to Ottoman mosques (Source: by the author)

Then the octagonal minaret which is a variant of the cylindrical minaret, it appeared in Tunisia in the 16th century with the arrival of Ottomans. It evokes Turkish influences because it reflects the "Hanafi" rite which became the rite of Tunisia at the Ottoman period while the square minaret which is a characteristic of the Arab hypostyle mosque reflects the belonging to the "Maliki" rite.

Thirdly, a strong link between between "mihrab" (component of central core $\mathrm{N}$ ) and the room of the "Imam" is identified. In fact, the collection subject of this study includes $86 \%$ of specimens with the segment I (the room of the imam) in the P1 position through continuities to the intermediate positions (P1-2 and P1-3). The segment I is adjacent to the prayer hall on the side where is the "mihrab". In the rest of specimens this segment cannot be placed on the side where the "mihrab" exists because the proportions of the terrain do not allow that; so segment $\mathrm{I}$ is located in position P2 or P3 so that it is in direct relation with the prayer hall. So we can identify this rule:

If the proportions of the plot make it possible, the room of the "Imam" is always placed in P1 position if not in P2 or P3 position so that it is directly related to the prayer hall.

Finally, the shape and the proportions of the parcel as well as the direction of the "qibla" are the determining factors of segments's form.

Indeed these extrinsic attributes can explain the spatial conformation of specimens's segments. In fact, the rapid changing of Tunis after the independence as well as new mode of urbanization induced to new mosques new forms to adapt the shape of Parcel which is assigned during the urban planning. Accordingly the direction of the "qibla" is no longer taken into account in subdivision; the latter is designated by a surveyor before the design of the mosque in question. Then the "qibla" wall is not always parallel to the axis of the street.
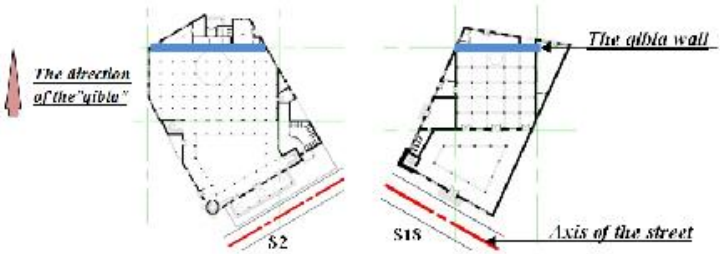

Figure 23. Specimens with segments having irregular forms (Source: by the author)

Schematically, we can summarize the process that makes the peripherals Px have irregular forms (sub-rectangular or sub-triangular) as shown at Figure 24

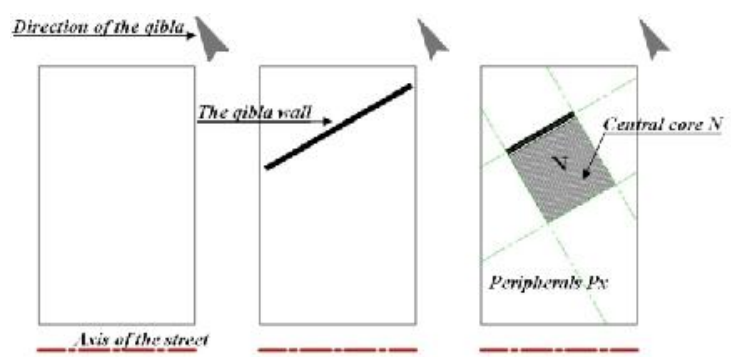

Figure 24. Peripherals irregularly shaped (Source: by the author)

Peripherals Px have regular forms when the "qibla" wall is either perpendicular or parallel to the axis of the street. Also the regular form of the plot has strongly contributed to the regularity of forms.

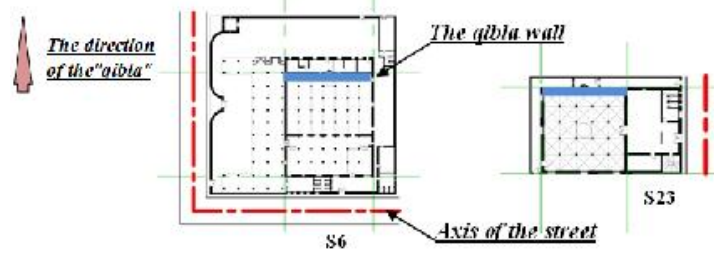

Figure 25. Specimens with segments having regular forms (Source: by the author) 
Schematically, we can summarize the process that makes the peripherals Px have regular forms as shown at figure 26 .
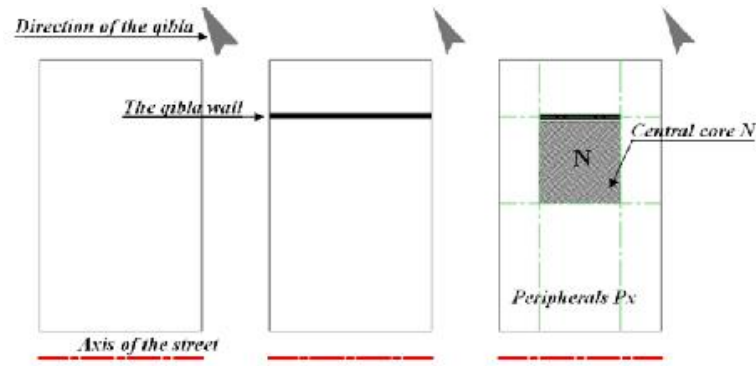

Figure 26. Peripherals regularly shaped (Source: by the author)

On the other hand the shape of the parcel can significantly affect the shape of the peripherals $\mathrm{Px}$, as is the case for the triangular plot.
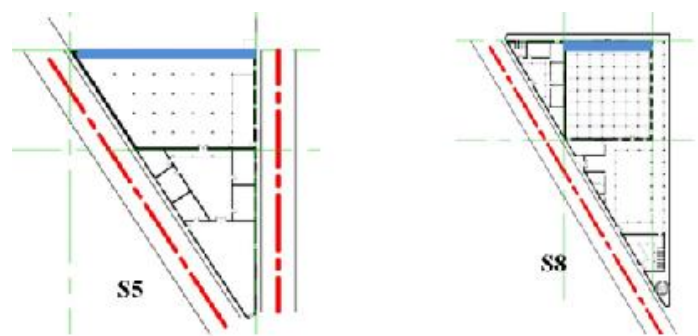

Figure 27. Forms of peripherals Px and forms of the plot (Source: by the author)

\footnotetext{
However, we can found peripherals having regular shapes although Parcel is irregular; especially when the land is large enough and allows implanting a mosque whose segments are regularly shaped.
}
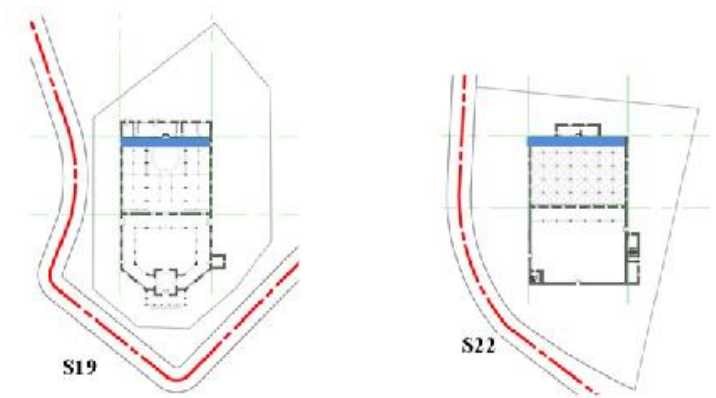

Figure 28. Forms of peripherals $\mathrm{Px}$ and proportions of the plot (Source: by the author)

\section{Conclusion}

In this paper we were interested in studying the morphology of 24 mosques built in the governorate of Tunis between 1975 and 1995. By using the morphological analysis we were able to focus on the internal organization of the plan which is composed of a central core $\mathrm{N}$ and a set of peripherals Px. The study of the position of these peripherals relative to the central core revealed a combinatorial system of spatial structure. In fact, the number of peripherals makes unity between classes while their positions allow structural diversity. Then the study of the conformation of the central core $\mathrm{N}$ showed that it has a plastic variation which can be related to its position in the parcel. Furthermore, the comparative decomposition of peripherals Px has allowed us to identify groups of homologous segments that have been the subject of a classificatory study according to the form and the position of their elementary conformations. We concluded that they have not only a plastic variety but also a disparity of positions that can be related to some extrinsic attributes such as access to the prayer hall, the orientation of the "qibla" or the shape and proportions of the parcel.

These results provide us with an important knowledge about these mosques and encourage us to further deepen our research. Indeed the results of our study cannot claim to be complete or exhaustive. This would require a broader point of view the number of specimens and point of view space-time corpus. Then one might consider the study of the mosque in its urban context and project a comparative study of the ancient and the new Tunisian mosques.

\section{Reference}

[1] U. Vogt-Göknil, Mosquées : Grands Courants de L'architecture Islamique, Paris, Le chêne, 1975.

[2] L.Golvin, La mosquée: ses origines, sa morphologie, ses diverses fonctions, son rôle dans la vie. Alger : Institut d'études supérieures islamiques d'Alger , 1960

[3] G.Marçais, L'art Musulman, Paris 1962

[4] G. Michell, Architecture of the Islamic World: Its Hisotry and Social Meaning. Thames and Hudson, Londres, 1978.

[5] T. Burckardt, L'art de l'Islam, langage et signification, Sindbad, Paris, 1985.

[6] Serageldin, J. Steele, Architecture of the Contemporary Mosque, Academy Editions, Londre,1996.

[7] Cetin, Murat, "Back to Future; Essence of Mosque Design and a New Generic Architectural Typology", in Lonaard Magazine, Vol. 1 Issue 3, pp65- 57, May 2011. 
[8] P.Sebag, Great Mosque of Kairouan, Macmillan, New York, 1965

[9] A. Lézine, Sousse: Les Monuments Musulmans, Cères productions, Tunis, 1968

[10] G. Marçais et L.Golvain, La Grande Mosquée de Sfax, Imprimerie La Rapide, Tunis, 1960

[11] Ben Mami, M.B., "La Mosquée Mohamed Bey, un Exemple de la Présence Architecturale et Artistique Ottomane dans la Médina de Tunis",Africa, Série A.T.P., $\mathrm{n}^{\circ} 12$, pp. 1-22.
[12] I. Cherif, Mosque of Tunis Gouvernorate Constructed Between 1975 and 1995: Morphological Knowledge and Modeling, unpublished Master's Thesis in Architecture supervised by Najla Allani Bouhoula, National School of Architecture and Urbanism, 2013.

[13] B. Duprat, Morphologie Appliquée: l'analyse des Conformations Architecturales, ses Problèmes, ses Principes, ses Méthodes, HDR, Lyonlll: Université jean moulin, Faculté de philosophie, 1999. 